\title{
THE MUSCULOSKELETAL SYSTEM INVOLVEMENT IN PATIENTS WITH INFECTIVE ENDOCARDITIS
}

\author{
Alexandra GREJDIERU ${ }^{1 凶}$, Elena SAMOHVALOV ${ }^{1}$, Lucia MAZUR-NICORICI ${ }^{1}$, Livi GRIB ${ }^{1}$ \\ ${ }^{1}$ Department of Internal Medicine, State University of Medicine and Pharmacy „Nicolae Testemitanu“, \\ Chisinau, Republic of Moldova
}

Received 08 Feb 2018, Accepted 29 Apr 2018

\begin{abstract}
Introduction. Infective endocarditis (IE) is a severe cardiovascular disorder involving native valves, ventricular or atrial endocardium, foreign intracardiac bodies (prosthetic valves, pacemaker or intracardiac defibrillator), and extracardiac (neurological, nephrological, musculoskeletal system etc.) complications with high mortality and poor prognosis.

The objectives of the study were to evaluate clinical and laboratory features of infective endocarditis with musculoskeletal manifestations.

Methods. The study was conducted on a sample of 235 patients, 185 being hospitalized in specialized Cardiology Departments, including four medical centers, between November 2014 and March 2016. All patients included in the study fulfilled the diagnostic criteria for infective endocarditis developed after Duke Endocarditis Service (Durham, North Carolina), revised in 1994 and 2007.
\end{abstract}

Results. According to the presence or absence of musculoskeletal manifestations (MSM), patients were divided in 2 groups: 1st group - 90 patients with IE and MSM (38\%) and 2nd group - 145 patients with IE without MSM (72\%). In this way we found that women develop musculoskeletal symptoms more frequently than men $-44 \%$ vs. $36 \%$, although MS symptoms were found in $38 \%$ of study patients. The highest
Résumé

\section{Affectation du système musculosquelettique chez les patients atteints d'endocardite infectieuse}

Introduction. L'endocardite infectieuse (EI) est un trouble cardiovasculaire grave portant sur les valves natives, l'endocarde ventriculaire ou auriculaire, des corps étrangers intracardiaques (valves prothétiques, pacemaker ou défibrillateur intracardiaque) et extracardiaques (système musculosquelettique, neurologique, néphrologique etc.) des complications avec une mortalité élevée et à mauvais pronostic.

Les objectifs étaient d'évaluer les caractéristiques cliniques et de laboratoire de l'endocardite infectieuse associée aux manifestations musculosquelettiques.

Méthodes. L'étude a été menée sur un échantillon de 235 patients, 185 étant hospitalisés dans les sections de cardiologie des départements spécialisés, y compris quatre centres médicaux, entre novembre 2014 et mars 2016. Tous les patients inclus à l'étude remplissant les critères diagnostiques de l'endocardite infectieuse développés selon Duke Endocarditis Service (Durham, Caroline du Nord), révisés en 1994 et 2007.

Résultats. Selon la présence ou l'absence de manifestations musculosquelettiques (MMS), les patients ont été divisés en 2 groupes: ler groupe - 90 avec EI et MMS (38\%) et 2ème groupe - 145 patients recevant une avec EI sans MMS (72\%). De cette façon, nous 
incidence of IE in the general study group was seen in men $-70 \%$ vs. women $-30 \%$ respectively $(p=0.022)$. Conclusions. From all predisposing cardiac factors in IE patients with MSM the most prevalent ones were: rheumatic valvular heart disease (33\%) and valvular prostheses $(24 \%)$, the predominant bacteremia source being the respiratory infections (52\%), poor dental hygiene (33\%) and tonsillitis (24\%) occurring in patients with diabetes mellitus (23\%) and hepatitis (21\%).

Keywords: infective endocarditis, musculoskeletal manifestations, complications.

Abbreviations: IE - infective endocarditis, MSM musculoskeletal manifestations, MS - musculoskeletal, NSAIDs - non steroid anti-inflammatory drugs.

\section{INTRODUCTION}

Infective endocarditis (IE) is a severe cardiovascular disorder involving native valves, ventricular or atrial endocardium, foreign intracardiac bodies (prosthetic valves, pacemaker or intracardiac defibrillator), leading to severe cardiac and extracardiac (neurological, nephrological, musculoskeletal, skin, etc.) complications with high mortality and poor prognosis. The disease, described in 1885 by William Osler, still remains a problem with complex and severe medical confrontation in the $21^{\text {st }}$ century. Despite significant progress in recent years, IE continues to be a severe illness, with difficulties regarding early and effective diagnosis treatment in many cases ${ }^{1}$.

\section{THE AIM OF THE STUDY}

The aim of the study was to evaluate clinical and laboratory features of infective endocarditis with musculoskeletal manifestations (MSM). The proposed objectives are:

1. Evaluation of predisposing cardiac factors, morbid circumstances and comorbidities in patients with IE and musculoskeletal manifestations as well as their impact on evolution and prognosis of the disease.

2. Estimation of blood culture results in study patients and echocardiography evaluation in patients with infective endocarditis and musculoskeletal signs.

\section{Material AND MEthods}

The study was conducted on a sample of 235 patients, 185 being hospitalized in specialized avons constaté que les femmes développent des symptômes musculosquelettiques plus fréquemment que les hommes - $44 \%$ par rapport à $36 \%$, bien que les symptômes de la MS aient été trouvés dans $38 \%$ des patients de l'étude. L'incidence la plus élevée dans le groupe d'étude générale d'EI a été observée chez les hommes - 70\% par rapport aux femmes - 30\% respectivement $(\mathrm{p}=0.022)$.

Conclusions. Parmi les facteurs de prédisposition cardiaques chez les patients d'EI avec MMS les plus fréquents étaient: la cardiopathie rhumatismale (33\%) et les prothèses valvulaires (24\%), la source de bactériémie prédominante étant les infections des voies respiratoires (52\%), l'hygiène dentaire impropre(33\%) et l'amygdalite (24\%) chez les patients atteints de diabète sucré (23\%) et l'hépatite (21\%).

Mots-clefs: endocardite infectieuse, manifestations musculosquelettiques, complications.

Cardiology Departments, including four medical centers from Chisinau, Republic of Moldova, between November 2014 and March 2016.

All patients included in the study fulfilled the diagnostic criteria for infective endocarditis developed after Duke Endocarditis Service (Durham, North Carolina), revised in 1994 and 2007.

According to study design, patients were divided in two groups: $1^{\text {st }}$ group - 90 patients with MSM (38\%) and $2^{\text {nd }}$ group - 145 patients without MSM (62\%). Men prevailed (70\%) with 164 cases compared to women 71 cases (30\%), male/female ratio being 2:1 which is similar to data presented in the literature ${ }^{2}$.

The primary material accumulated in the statistical observation phase was used to create the database using Excel. The results of the research were subsequently evaluated, the veracity of advanced theories was estimated according to homogeneity of two selections verification test - $(\mathrm{t})$-Student.

\section{Results AND DISCUSSION}

We examined patients with IE and MSM thoroughly, in order to determine clinical, laboratory, treatment, prognosis and prevention features. Afterwards, we compared them to patients with IE without MSM, in order to delineate some evolution, diagnosis and treatment features.

According to the presence or absence of MSM, patients were divided in 2 groups: $1^{\text {st }}$ group $-90 \mathrm{pa}-$ tients with IE and MSM (38\%) and $2^{\text {nd }}$ group - 145 patients with IE without MS symptoms (72\%). In this way, we found that women develop musculoskeletal symptoms more frequently than men $-44 \%$ vs. $36 \%$, 
although MS symptoms were found in 38\% of study patients. The highest incidence of IE in the general study group was seen in men $-70 \%$ vs. women $30 \%$ respectively $(\mathrm{p}=0.022)$.

Of the total number of patients with musculoskeletal symptoms $(n=90)$, patients with arthralgia were predominant $-40 \%$ cases, followed by patients with myalgia in $22.5 \%$ cases, back pain in $23.3 \%$ cases, $33.3 \%$ of these cases being of renal origin, while $66.6 \%$ of extrarenal origin, arthritis in $10 \%$ cases. Data on incidence of arthralgia, back pain and myalgias are similar to those described in the literature ${ }^{3}$.

When assigning patients with IE and MSM according to the timing of MS events, we noticed that 30 (33\%) patients experienced MS symptoms at disease onset, while 60 (67\%) patients had MSM during the course of the disease, this feature being influenced by the body's immune status, the causing bacterial agent and its virulence ${ }^{4}$.

We note that bacteremia morbid circumstances in both study groups showed statistical differences. In IE with MSM cases, respiratory infections prevailed in $52 \%$ of cases followed by poor dental hygiene in $33 \%$ cases, frequent tonsillitis in $24 \%$ cases, surgeries and dental extractions in 22\% and 19\% cases respectively. Similarly, respiratory infections predominated in IE without MSM in $42 \%$ of cases, poor dental hygiene in $25 \%$ cases. Tonsillitis was reported in $18 \%$ of cases followed by surgery in $16 \%$ cases and urinary infections in $11 \%$ cases, which allow us to identify infection site in IE. The circumstances mentioned above prevail in IE cases with MSM compared to IE without MSM.

Another aspect of IE in our study was comorbidities assessment in both study groups. Equal incidence of renal failure was determined in both study groups in $31 \%$ of cases, this being the most prevalent comorbidity in comparison to other ones. A higher rate of comorbidities among patients with IE and MSM was: diabetes in 23\% of cases, hepatitis in $21 \%$ of cases versus $12 \%$ and $15 \%$ of cases in patients with IE but no MSM respectively, cirrhosis in $7 \%$ versus $11 \%$ of cases $(p<0.05)$.

Given the fact that definite diagnosis of IE is established according to two major criteria, one of them being positive blood culture, we examined blood culture results in our patients and noticed that $40 \%$ of IE patients with MS manifestations had positive blood cultures, while $60 \%$ of cases had negative ones $(\mathrm{p}<0.05)$. In IE patients without MSM blood cultures were positive in $30 \%$ of cases, being negative in $70 \%$ cases $(\mathrm{p}=0.06)$.

In addition, we emphasized microbial spectrum features in both study groups Staphylococci predominating overall in $48 \%$ of IE cases with MSM and $61 \%$ in those with IE without MS symptoms. Streptococcal spectrum was higher in IE patients with MSM, 25\% cases for the Streptococcus pyogenic in 3\% cases for the Streptococcus viridans - 1\%, compared to IE patients without MSM, Streptococcus pyogenic 5\% cases and Streptococcus viridans in 5\% cases. Enterococci and Fungi infections prevailed in IE patients without MSM - $18 \%$ and $11 \%$ cases, while in IE patients with MSM, Enterococci were determined in 16\% of cases, and Fungi in $8 \%$ of cases only. According to the literature, the etiologic microbial agent in the majority of cases is Staphylococcus aureus (31.2\% cases), leading to septic or reactive arthritis with severe involvement in adults. Streptococcal species come next, especially group A Streptococcus, which usually infects joints through skin or soft tissues infections 4,5 .

In the current study, we noticed that NSAIDs administration was higher compared to corticosteroids, $80 \%$ of IE patients with MS manifestations taking NSAIDs and only $27 \%$ taking corticosteroids. By analyzing IE patients with MS manifestations, 54\% were hospitalized up to 20 days ( 3 weeks), the period of hospitalization in $45 \%$ of cases being more than 20 days, our data being similar to the literature data studied $^{6}$.

In recent decades, population's life expectancy has increased, influencing IE incidence, depending on patients' increasing age, 60-79 years of age, and being caused by associated comorbidities and immunosuppression ${ }^{6}$. Moreover, in developing countries, rheumatic valvular heart disease remains the most common predisposing factor for IE development, while in highly developed countries these diseases have a significant eradication? ${ }^{7}$ A local study conducted at the Institute of Cardiology on a group of 408 patients with IE, during the 1992-2007 period, highlighted some features of IE patients from Moldova: younger age compared to patients from Western countries, prevalence of rheumatic heart disease in predisposing cardiac pathologies profile, frequent morbid circumstances, dental infections, poor dental hygiene and dental manipulations ${ }^{8}$.

According to the literature, musculoskeletal manifestations in patients with IE are part of the complex symptomatology, their presence worsening the clinical course of the disease and increasing the duration of hospitalization. In some instances, these symptoms may arise at onset of the disease in the absence of specific IE clinical signs, causing difficulties in diagnosis establishment and consequently, appropriate treatment initiation ${ }^{9 \cdot 10}$. However, musculoskeletal changes occur more frequently during the course of the disease and represent manifestations of its complications, more frequently neurological and embolic ones. Cases reported in literature describe 
episodes of arthritis and back pain. Prospective cohort studies report an incidence of $28-50 \%$ cases of musculoskeletal manifestations in patients with IE: arthralgia $30 \%$, arthritis $6.4 \%$, synovitis $2.8 \%$, myalgia $20 \%$ and back pain $16 \%$ 2,3,11-16.

Taking into account the aggravated course of IE disease with musculoskeletal manifestations, treatment features and impaired quality of life in these patients, we aimed to study IE incidence, clinical course features and prognosis in patients from Moldova and to estimate some specific features in this area, hoping this paper to be of support in establishing the diagnosis early and facilitating appropriate etiopathogenetic treatment initiation in patients with IE and musculoskeletal manifestations.

\section{Conclusions}

From all predisposing cardiac factors in IE patients with MS manifestations, the most prevalent ones were: rheumatic valvular heart disease (33\%) and valvular prostheses (24\%), the predominant bacteremia source being respiratory infections (52\%), poor dental hygiene (33\%) and tonsillitis (24\%) occurring in patients with diabetes mellitus (23\%) and hepatitis (21\%). In patients with endocarditis and MS symptoms, toxic-infective syndrome (96\%), signs of heart failure (88\%) arthralgia and myalgia, $24.4 \%$ and $40 \%$ respectively, were more marked. Positive blood cultures were seen in $40 \%$ cases, with Staphylococcus (48\%) and Streptococcus (28\%) trigger predominance. Echocardiography exams revealed aortic valve (38\%), mitral valve (31\%) and tricuspid valve (13\%) vegetations and ruptured of chordae (24\%).

\section{Compliance with Ethics Requirements:}

„The authors declare no conflict of interest regarding this article"

"The authors declare that all the procedures and experiments of this study respect the ethical standards in the Helsinki Declaration of 1975, as revised in 2008(5), as well as the national law. Informed consent was obtained from all the patients included in the study"

\section{References}

1. Habib G, Lancellotti P, Antunes M et al. ESC Guidelines for the management of infective endocarditis. The Task Force for the Management of Infective Endocarditis of the European Society of Cardiology (ESC). European Heart Journal 2015; 36(44): 3075-3128.

2. Hill EE, Herijgers P, Claus P et al. Infective endocarditis: changing epidemiology and predictors of 6-month mortality: a prospective cohort study. Eur Heart J 2007; 28(2):196-203.

3. Rangel E, Atallah A. Musculoskeletal manifestations of bacterial endocarditis. Sao Paulo Med. J. 2000; 118(5):158-160.

4. González-Juanatey C, González-Gay MA, Llorca J, et al. Rheumatic manifestations of infective endocarditis in non-addicts. A 12-year study. Medicine (Baltimore). 2001; 80(1):9-19.

5. Mocchegiani R, Nataloni M. Complications of infective endocarditis. Cardiovasc Hematol Disord Drug Targets. 2009; 9(4):240-248.

6. Murdoch DR, Corey GR, Hoen B, Miró JM. Clinical presentation, etiology, and outcome of infective endocarditis in the 21st century: the International Collaboration on Endocarditis-Prospective Cohort Study. Arch Intern Med. 2009;169 (5):463-73.

7. Wang A, Athan E, Pappas PA, et al. Contemporary clinical profile and outcome of prosthetic valve endocarditis. JAMA 2007; 297(12):1354-61

8. Știrbul A, Grejdieru A, Mazur M et al. Endocardita infecțioasă profilul clinic, prezentare și evoluție. Buletinul Academiei de Științe a Moldovei, Chișinău 2008; 4(18):90-96.

9. López-Dupla M, Hernández $\mathrm{S}$ et al. Clinical characteristics and outcome of infective endocarditis in individuals of the general population managed at a teaching hospital without cardiac surgery facilities. Study of 120 cases. Rev Esp Cardiol, 2006; 59(11): 1131-1139.

10. DeSimone DC, Tleyjeh IM, et al. Temporal trends in infective endocarditis epidemiology from 2007 to 2013 in Olmsted County, MN. Am Heart J. 2015;170(4):830-836.

11. Olmos C, Vilacosta I, Fernández-Pérez $\mathrm{C}$ et al. The evolving nature of infective endocarditis in Spain: a population-based study (2003 to 2014). J Am Coll Cardiol. 2017; 70 (22):2795-2804.

12. Thuny, F, Grisoli, D, Cautela, J, Riberi, A, Raoult, D, Habib, G. Infective endocarditis: prevention, diagnosis, and management. Can J Cardiol 2014; 30: 1046-1057.

13. Garcia-Porrua, C, Gonzalez-Juanatey, C, Gonzalez-Gay, MA. Rheumatic manifestations as presenting signs of infective endocarditis. Clin Exp Rheumatol 2001; 19: 763-764.

14. Ying, CM, Yao, DT, Ding, HH, Yang, CD. Infective endocarditis with antineutrophil cytoplasmic antibody: report of 13 cases and literature review. PLoS One 2014; 9: e89777e89777.

15. Song, JK. Infective endocarditis involving an apparently structurally normal valve: new epidemiological trend? Korean J Intern Med 2015; 30: 434-442.

16. Siciliano, RF, Mansur, AJ, Castelli, JB. Community-acquired culture-negative endocarditis: clinical characteristics and risk factors for mortality. Int J Infect Dis 2014; 25: 191-195. 